\title{
Proteomic Identification of FLT3 and PCBP3 as Potential Prognostic Biomarkers for Pancreatic Cancer
}

\author{
MARIJA GER $^{1}$, ALGIRDAS KAUPINIS ${ }^{1}$, MARIUS PETRULIONIS ${ }^{2,3}$, BENEDIKTAS KURLINKUS $^{3}$, \\ JONAS CICENAS ${ }^{1,4,5}$, AUDRIUS SILEIKIS ${ }^{2,3}$, MINDAUGAS VALIUS ${ }^{1}$ and KESTUTIS STRUPAS ${ }^{2,3}$ \\ ${ }^{1}$ Institute of Biochemistry, Proteomics Center, Vilnius University Life Sciences Center, Vilnius, Lithuania; \\ ${ }^{2}$ Center of Abdominal Surgery, Vilnius University Hospital Santaros Klinikos, Vilnius, Lithuania; \\ ${ }^{3}$ Clinic of Gastroenterology, Nephrourology and Surgery, Faculty of Medicine, Vilnius University, Vilnius, Lithuania; \\ ${ }^{4}$ MAP Kinase Resource, Bioinformatics, Bern, Switzerland; \\ ${ }^{5}$ Department of Microbiology, Immunology and Genetics, \\ Max F. Perutz Laboratories, University of Vienna, Vienna, Austria
}

\begin{abstract}
Background/Aim: Pancreatic ductal adenocarcinoma (PDAC) is one of the deadliest types of cancer, particularly due to its aggressive course and challenging diagnostics in earlystage disease. The aim of this study was to discover new potential prognostic and diagnostic pancreatic cancer biomarkers. Materials and Methods: The proteomes of 37 samples from pancreatic cancer, inflammatory or healthy pancreatic tissue derived through in-depth differential proteomic analysis were compared. Results: A set of candidate proteins as pancreatic cancer-specific diagnostic or prognostic biomarkers were identified. Survival data of patients after two-year followup indicated FLT3 and PCBP3 proteins as potential biomarkers for favourable pancreatic cancer prognosis. The levels of PCBP3 correlated with tumour stage and FLT3 levels, were evaluated as independent prognostic marker. Conclusion: FLT3 and $P C B P 3$ represent potential biomarkers for improved individualized pancreatic cancer prognosis. Moreover, FLT3 may play a role in future treatment selection.
\end{abstract}

Pancreatic cancer is the fourth leading cause of cancer-related deaths in the European population. Contrary to the most other cancer types, the rate of pancreatic cancer mortality is still increasing with the predicted numbers of deaths in year 2017 to be around 7.9 out of 100,000 in men and 5.6 out of 100,000 in women (1). Similarly, high incidence and mortality rates of pancreatic cancer are also observed in the USA with potential to become one of the three leading cancer death causes during the next two decades $(2,3)$.

Correspondence to: Marija Ger, Institute of Biochemistry, Proteomics Center, Vilnius University Life Sciences Center, Vilnius, Lithuania. Tel: +370 52234411, e-mail: marija.ger@bchi.vu.lt

Key Words: Pancreatic cancer, proteomic analysis, biomarkers.
It is known, that pancreatic cancer carcinogenesis is a prolonged process, involving certain genetic alterations and modified expression of many proteins and metabolites, that usually follows pancreatic intraepithelial neoplasia (PanIN) within pancreatic tissue before development of adenocarcinoma (4-6). The conventional serum biomarkers carbohydrate antigen 19-9 (CA 19-9) and carcinoembryonic antigen (CEA) are neither very specific nor sensitive for early pancreatic cancer and are mostly used for follow-up of pancreatic ductal adenocarcinoma (PDAC) patients in response to treatment, but not for screening for pancreatic malignancies $(7,8)$. The intensive search for specific and sensitive biomarkers to be used for screening of PDAC focuses on proteome and metabolome of different body fluids and tissues, as well as on the detection of genetic, epigenetic, exosomic, microbiomic, micro-RNA and other biomarkers (7, $9,10)$. There is also lack of molecular classification and successful targeted therapies for pancreatic cancer (11).

The aim of this study was to find new protein biomarkers for pancreatic cancer diagnosis and survival prognosis. In quantitative proteomic analysis, tumour samples were compared to healthy pancreas tissue samples; chronic pancreatitis samples were used as additional control to eliminate unspecific inflammation-related proteins. The expression levels of the discovered potential biomarkers were correlated with patients' medical data.

\section{Materials and Methods}

Patient data and tissue samples. Tissue specimens from 37 patients were included in the analysis: 19 pancreatic cancer samples, 10 samples of chronic pancreatitis and also 8 samples of healthy pancreas tissue that were obtained from specimens after surgery for benign pancreas or duodenum diseases. All patients have read and signed the form of informed consent for taking part in the research, approved by Lithuanian Bioethical Committee (Protocol No. 
PancCa001-3). Patients with adenocarcinoma underwent radical surgery. Chronic pancreatitis group of patients underwent 9 standard Frey's procedures and 1 pylorus preserving pancreaticoduodenal resection. Patients with benign pancreas or duodenum conditions underwent surgical treatment depending on the pathology.

All diagnoses were confirmed by histological examination of tissue specimens by an experienced pathologist. Tumour sizes were determined by pathohistological examination of findings. Chronic pancreatitis diagnosis was confirmed pathologically. The process of freezing the specimens was identical to that described by Börner $e t$ al. (12). Within less than $10 \mathrm{~min}$ after resection, tissue samples were frozen in liquid nitrogen in cryotubes. After transportation period of $10 \mathrm{~min}$, the samples were placed in a freezer and kept at a temperature of $-80^{\circ} \mathrm{C}(12)$.

Proteomic sample preparation. To examine disease associated changes in the proteome, high-throughput differential label-free quantitative proteomic analysis of healthy, pancreatic carcinoma and pancreatitis patient samples was performed using high-definition mass spectrometry (HDMS) technology. In addition, pancreatic carcinoma samples were divided into 2 groups: tumours larger than $3 \mathrm{~cm}$ and $2 \mathrm{~cm}$ or smaller.

Homogenized samples were lysed using Urea/Thiourea lysis buffer and sonicated for $1 \mathrm{~min}$ at the amplitude of $20 \%$ and $0.4 \mathrm{sec}$ pulsations on/off cycles. Lysates were centrifuged at 20,000 $\times \mathrm{g}$ for $15 \mathrm{~min}$ at $4^{\circ} \mathrm{C}$, and the supernatants were collected and stored at $-80^{\circ} \mathrm{C}$. Trypsin digestion was performed according to a modified filter aided sample preparation (FASP) protocol as described previously (13).

LC-MS analysis. Liquid chromatography (LC) separation of peptides was performed with nanoAcquity UPLC system (Waters Corporation, Elstree, UK) on reversed-phase trap column as described previously (13). Data were acquired using Masslynx version 4.1 software (Waters Corporation) in positive ion mode. LC-MS data were collected using data independent acquisition (DIA) mode MSE in combination with online ion mobility separation.

The trap collision energy of mass spectrometer was ramped from 18 to $40 \mathrm{eV}$ for high-energy scans in MSE mode. The trap and transfer collision energy for high-energy scans in HDMS mode was ramped from 4 to $5 \mathrm{eV}$ and from 27 to $50 \mathrm{eV}$. For both analyses, the mass range was set to $50-2,000 \mathrm{Da}$ with a scan time set to $0.9 \mathrm{sec}$. The reference compound [Glu1]-Fibrinopeptide B (Waters Corporation) was infused continuously $(500 \mathrm{fmol} / \mu \mathrm{l}$ at flow rate $500 \mathrm{nl}$ per min) and scanned every $30 \mathrm{sec}$ for on-line mass spectrometer calibration purpose. The samples were run in triplicate.

Data processing, searching and analysis. Raw data files were processed and searched using ProteinLynx Global SERVER (PLGS) version 2.5.3 (Waters Corporation). The following parameters were used to generate peak lists: (i) minimum intensity for precursors was set to 150 counts; (ii) minimum intensity for fragment ions was set to 50 counts; (iii) intensity was set to 500 counts. Processed data were analysed using trypsin as the cleavage protease, one missed cleavage was allowed, fixed modification was set to carbamidomethylation of cysteines and variable modification was set to oxidation of methionine. Minimum identification criteria included 1 fragment ions per peptide, 3 fragment ions per protein and minimum of 2 peptides per protein. The false discovery rate (FDR) for peptide and protein identification was determined based on the search of a reversed database generated automatically when global false discovery rate was set to $4 \%$. UniProtKB/SwissProt human database (2018-02-05) was used for protein identification.

Computational analysis of proteomic data. For quantitative analysis of global proteome, increase or decrease in protein level of 1.5-fold or more was considered as up-regulation or down-regulation, respectively, with $p$-value $\leq 0.05$. Kaplan-Meier survival analysis with Log-Rank test was performed using SigmaPlot 11.0 statistical software (Systat Software Inc., San Jose, USA).

\section{Results}

Differential global proteomics of chronic pancreatitis $(C P)$ and pancreatic ductal adenocarcinoma (PDAC) samples. Tissue samples from 37 patients with pancreatic cancer, $\mathrm{CP}$ or healthy pancreatic tissue were analyzed. The samples were fractionated and analyzed by HDMS in two series of proteomic experiments. Nineteen to twenty tissue samples were analysed in each series, 3192 proteins in total in all patient proteomes were identified and quantified.

Proteins were considered differentially regulated, when their levels were significantly $(p \leq 0.05)$ increased or decreased by 1.5 -fold and higher in CP or PDAC patients versus control pancreatic tissue samples in both series of experiments. In CP, 171 differentially regulated proteins were identified; 156 - increased and 15 decreased. In PDAC, 519 differentially regulated proteins were found; 333 increased and 186 decreased. PCA analysis of protein identification data (Figure 1) showed that control, $\mathrm{CP}$ and PDAC samples split into separate groups (with exception of one PDAC sample) with CP falling in a group between the control and tumour tissue. The differences in proteome of smaller $(>2 \mathrm{~cm})$ and larger $(<3 \mathrm{~cm})$ PDAC tumours can also be distinguished by PCA analysis.

Comparative proteomics of smaller and larger PDAC tumours. The study was designed to elucidate not only the difference between $\mathrm{CP}$ and PDAC but also to compare smaller $(>2 \mathrm{~cm})$ and larger $(<3 \mathrm{~cm})$ tumour proteomes. There were indeed some differences in smaller versus larger tumour specimens. In particular, three proteins were significantly increased in smaller compared to larger tumours: PCBP3, HBE1 and RHOB. Three other proteins were increased in larger tumours: GPRC5A, KRT13 and GNAT3. All six proteins, characteristic to smaller or larger tumours, were considered as candidate diagnostic and prognostic biomarkers that could potentially add to treatment selection. These proteins were also included in correlation analysis with patient's survival as described below.

PDAC biomarker analysis. Proteomic analysis revealed a number of proteins detected exclusively in patients with PDAC, but not in chronic pancreatitis patients or in healthy 

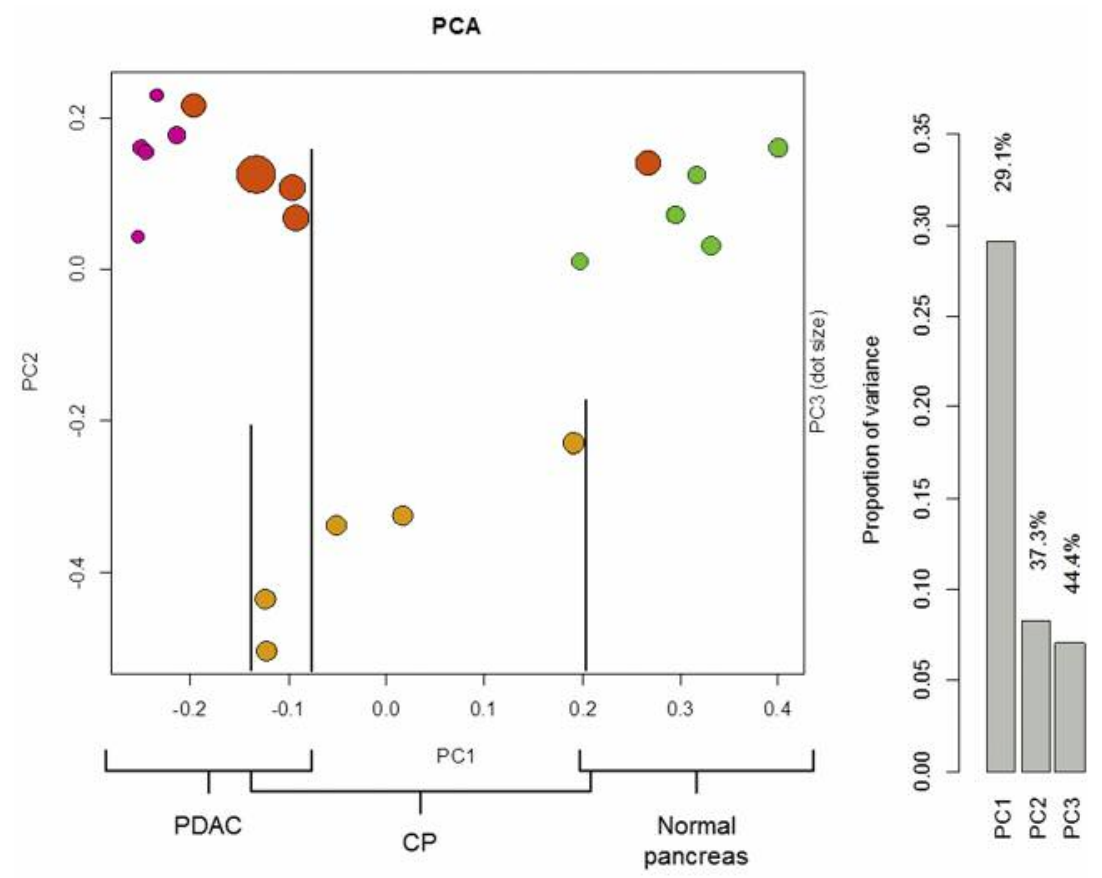

Figure 1. PCA analysis of protein identification data highlighted overlaps and differences between chronic pancreatitis and pancreatic ductal adenocarcinoma.

Table I. List of potential PDAC biomarkers.

\begin{tabular}{lccc}
\hline Gene name & Name & $\begin{array}{c}\text { Percentage of patients } \\
\text { expressing the marker }\end{array}$ & $\begin{array}{c}\text { Prognostic marker (unfavourable) } \\
\text { (HPA pathology data) }\end{array}$ \\
\hline THBS3 & Thrombospondin-3 & 79 & Renal, endometrial, colorectal cancer \\
FLT3 & Receptor-type tyrosine-protein kinase FLT3 & 79 & - \\
GPRC5A & Retinoic acid-induced protein 3 & 79 & PDAC, renal cancer \\
MYO1F & Unconventional myosin-If & 58 & Renal cancer \\
GPX2 & Glutathione peroxidase 2 & 52 & Head and neck cancer \\
KRT23 & Keratin, type I cytoskeletal 23 & 42 & Urothelial cancer \\
PSCA & Prostate stem cell antigen & 42 & PDAC \\
S100A14 & Protein S100-A14 & 42 & - \\
LGALS9C & Galectin-9C & 37 & -
\end{tabular}

pancreatic tissue. We selected 9 PDAC-specific proteins detected in 37-79 \% of all PDAC patients as potential diagnostic or prognostic markers (Table I). For estimation of the potential value of the biomarker candidates, data from The Human Protein Atlas database were employed. The data showed that most of the selected proteins are already known as potential prognostic markers in other cancer types such as renal, endometrial as well as urothelial cancer. GPRC5A (14) and PSCA $(15,16)$ proteins have already been reported as potential prognostic markers with unfavourable outcome for pancreatic cancer.
Survival analysis of patients. The levels of proteins varying between smaller or larger tumours as well as those of the selected PDAC-specific candidate biomarkers were correlated with the survival of the patients, monitored during the two years after the surgery. Significant correlation between patient survival and the levels of FLT3 or PCBP3 (Figure 2) proteins in postoperative tissue was established. The expression of both markers correlated with better 24 months survival compared to PDAC patients without detectable expression of FLT3 $(p=0.01)$ and PCBP3 $(p=0.043)$ in tumour tissue. The correlation of 

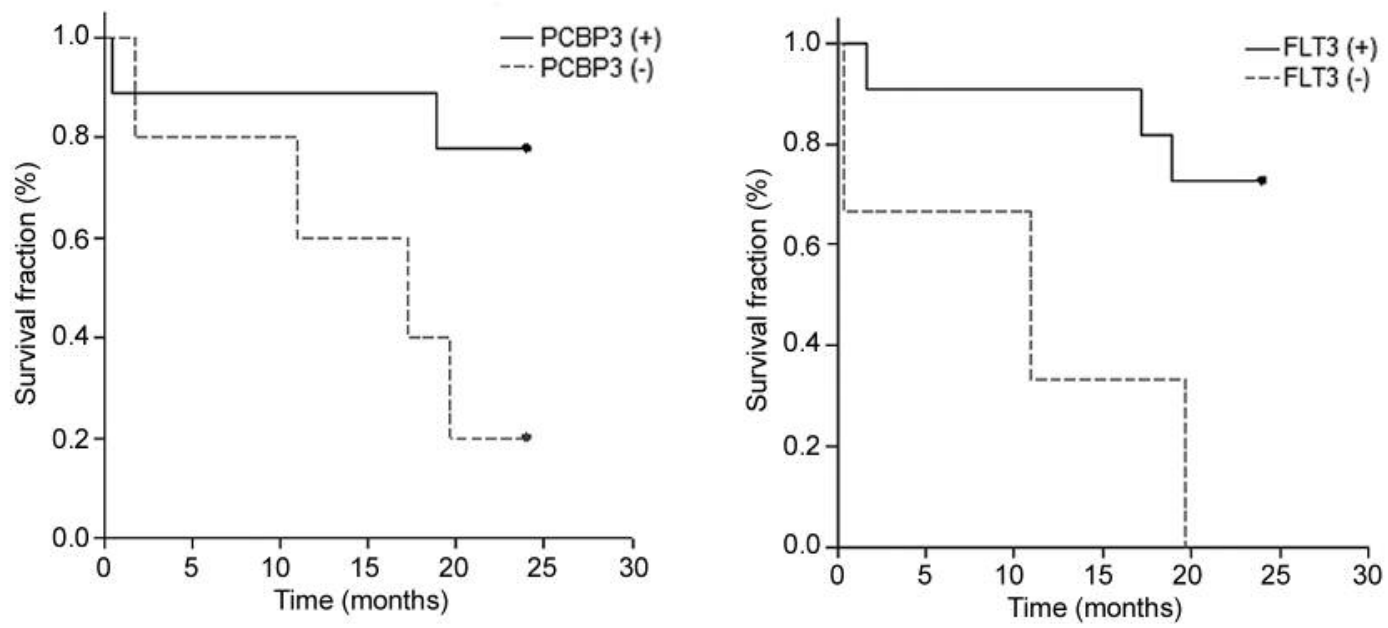

Figure 2. FLT3 and PCBP3 expression in patient samples correlated with increased survival.

Table II. Association of PCBP3 expression with patients' clinical data.

\begin{tabular}{|c|c|c|c|c|}
\hline \multirow[t]{2}{*}{ Variable } & \multirow{2}{*}{$\begin{array}{c}\text { No. of } \\
\text { cases }\end{array}$} & \multicolumn{2}{|c|}{ PCBP3 expression } & \multirow[t]{2}{*}{$p$-Value } \\
\hline & & Negative & Positive & \\
\hline \multicolumn{5}{|l|}{ Age } \\
\hline$\leq 65$ & 13 & 4 & 9 & 0.417 \\
\hline$>65$ & 7 & 1 & 6 & \\
\hline \multicolumn{5}{|l|}{ Gender } \\
\hline Male & 10 & 3 & 7 & 0.606 \\
\hline Female & 10 & 2 & 8 & \\
\hline \multicolumn{5}{|l|}{ Stage } \\
\hline IIA & 8 & 0 & 8 & 0.035 \\
\hline IIB & 12 & 5 & 7 & \\
\hline \multicolumn{5}{|c|}{ Lymph node invasion } \\
\hline Positive & 12 & 5 & 7 & 0.035 \\
\hline Negative & 8 & 0 & 8 & \\
\hline \multicolumn{5}{|c|}{ Tumour differentiation } \\
\hline Moderate & 15 & 4 & 11 & 0.766 \\
\hline Poor & 5 & 1 & 4 & \\
\hline \multicolumn{5}{|c|}{ Perineural invasion } \\
\hline Positive & 8 & 3 & 5 & 0.291 \\
\hline Negative & 12 & 2 & 10 & \\
\hline \multicolumn{5}{|c|}{ Radical resection } \\
\hline Positive & 16 & 4 & 12 & 1.000 \\
\hline Negative & 4 & 1 & 3 & \\
\hline
\end{tabular}

FLT3 and PCBP3 expression with other clinical parameters was also evaluated. Data showed that expression of PCBP3 in patients was associated with tumour stage and lymph node invasion (Table II). On the contrary, expression of
Table III. Association of FLT3 expression with patients' clinical data.

\begin{tabular}{lrrrr}
\hline Variable & \multirow{2}{*}{$\begin{array}{c}\text { No. of } \\
\text { cases }\end{array}$} & \multicolumn{2}{c}{ FLT3 expression } & \multirow{2}{*}{-Value } \\
\cline { 3 - 4 } & & Negative & Positive & \\
\hline Age & & & & \\
$\quad \leq 65$ & 13 & 2 & 11 & 0.482 \\
$>65$ & 7 & 2 & 5 & \\
Gender & & & & \\
$\quad$ Male & 10 & 3 & 7 & 0.264 \\
$\quad$ Female & 10 & 1 & 9 & \\
Stage & & & & \\
$\quad$ IIA & 8 & 1 & 7 & 0.494 \\
IIB & 12 & 3 & 9 & \\
Lymph node invasion & & & & \\
$\quad$ Positive & 12 & 3 & 9 & 0.494 \\
$\quad$ Negative & 8 & 1 & 7 & \\
Tumour differentiation & & & & \\
$\quad$ Moderate & 15 & 4 & 11 & 0.197 \\
$\quad$ Poor & 5 & 0 & 5 & \\
Perineural invasion & & & & \\
$\quad$ Positive & 8 & 1 & 7 & 0.494 \\
$\quad$ Negative & 12 & 3 & 9 & \\
Radical resection & & & & \\
$\quad$ Positive & 16 & 3 & 13 & 0.780 \\
$\quad$ Negative & 4 & 1 & 3 & \\
\hline
\end{tabular}

FLT3 did not correlate with any of the analyzed clinical parameters (Table III) presenting FLT3 as promising independent biomarker for better survival of PDAC patients. 


\section{Discussion}

In case of pancreatic cancer, the surgery at the early stages of the disease is the best option for increasing the survival of patients. Scientists and healthcare providers worldwide are striving to find new methods for early diagnosis of pancreatic cancer. Improved imaging technologies did not bring the expected advances to date and therefore, cannot be applied as a first-choice screening methods in large populations.

As a result, biomarker research seems to be one of the most promising solutions to find the means for screening, diagnosis, prognosis and therapy prediction of pancreatic cancer.

In this study, in-depth high-throughput differential proteomic analysis for the discovery of pancreatic cancerspecific biological processes and potential PDAC biomarkers was applied. Pancreatic cancer tumour samples were compared to pancreatic tissue samples from healthy individuals as well as from individuals with chronic pancreatitis. PCA analysis showed chronic pancreatitis (CP) as an intermediate condition between normal and pancreatic cancer supporting the current consensus that both conditions are interdependent (17). Bioinformatic analysis of Gene Ontology category enrichment of differentially expressed proteins confirms this statement by demonstrating that all main biological processes altered in chronic pancreatitis are also enriched in PDAC proteome (data not shown). CP has for a long time been known as risk factor for pancreatic intraepithelial neoplasia (PanIN) (17). In mouse models, it has directly been shown how CP leads to PanIN formation from KRAS-mutated cells (18). Accurate distinction between processes altered in both $\mathrm{CP}$ and PDAC and the identification of specific PDAC malignant features are crucial for early pancreatic cancer diagnostic as well as for effective treatment selection.

Our work demonstrated that the expression of FLT3 and PCBP3 correlated with favourable prognosis. PCBP3 belongs to a family $\mathrm{s}$ of RNA-binding proteins that interact in a sequence-specific manner with single-stranded poly $(\mathrm{C})$ RNA (19). PCBPs are also capable of binding single-strand DNA elements and PCBP3 acts as transcription suppressor $(20,21)$. According to The Human Protein Atlas, this gene is expressed at high to medium levels in 8 of the 11 patients with pancreatic cancer. No data associated PCBP3 with carcinogenesis. However, overexpression of its counterpart PCBP4 in human maxillary cancer cells led to the $G_{2} / M$ arrest and contributed to cisplatin resistance (22).

FLT3 is a receptor tyrosine kinase expressed primarily in haematopoietic progenitor cells. The earlier data based in immunohistochemical staining showed heterogeneity of FLT3 expression in normal pancreatic tissue and pancreatic cancer, the highest level of FLT3 being characteristic to ductal cancer cells (23). On the other hand, FLT3-ligand is a growth factor that directs the development and maturation of dendritic cells (DC) (24). DC are usually present in low numbers in the pancreatic tumour and tumour microenviroment and often in an immature form $(25,26)$. The presence of DC along with other tumour-infiltrating lymphocytes in PDAC serves as a good indicator of patient's outcome after surgical treatment (26) and has repeatedly been proposed as a marker of "immune rich" (27) or "immunogenic" (28) pancreatic cancer subtype characterized by better outcome. Thus, correlation of FLT3 expression in PDAC patients with better survival may be explained by the significant increase of tissue DC population that coordinates innate and adaptive immune response. Therefore, FLT3 expression may serve as biomarker of DC population in PDAC. Notably, DC-based vaccines against pancreatic cancer are now being tested in phase II/III studies (29). Moreover, FLT3 ligand that acts via FLT3 manifests antitumor activity (30) and is considered as potential adjuvant for immunotherapy (31).

Altogether, our data propose that FLT3 expression should be considered an important prognostic marker for individualized immunotherapeutic response and PCBP3 is a promising survival marker for PDAC patients.

\section{Conflicts of Interest}

Authors declare that they have no conflicts of interest regarding this study.

\section{Acknowledgements}

This project was funded by "Healthy Ageing" programme of the Research Council of Lithuania; funding contract no. SEN-01/2016 / LSS-150000-1269.

\section{References}

1 Malvezzi M, Carioli G, Bertuccio P, Boffetta P, Levi F, La Vecchia $C$ and Negri E: European cancer mortality predictions for the year 2017, with focus on lung cancer. Ann Oncol 28: 1117-1123, 2017.

2 Rahib L, Smith BD, Aizenberg R, Rosenzweig AB, Fleshman JM and Matrisian LM: Projecting cancer incidence and deaths to 2030: the unexpected burden of thyroid, liver, and pancreas cancers in the United States. Cancer Res 74: 2913-2921, 2014.

3 Siegel RL, Miller KD and Jemal A: Cancer statistics, 2017. CA Cancer J Clin 67: 7-30, 2017.

4 Brosens LAA, Hackeng WM, Offerhaus GJ, Hruban RH and Wood LD: Pancreatic adenocarcinoma pathology: changing "landscape". J Gastrointest Oncol 6: 358-74, 2015.

5 Waddell N, Pajic M, Patch A-M, Chang DK, Kassahn KS, Bailey P, Johns AL, Miller D, Nones K, Quek K, Quinn MCJ, Robertson AJ, Fadlullah MZH, Bruxner TJC, Christ AN, Harliwong I, Idrisoglu S, Manning S, Nourse C, Nourbakhsh E, Wani S, Wilson PJ, Markham E, Cloonan N, Anderson MJ, Fink JL, Holmes O, Kazakoff SH, Leonard C, Newell F, Poudel B, Song S, Taylor D, Waddell N, Wood S, Xu Q, Wu J, Pinese M, 
Cowley MJ, Lee HC, Jones MD, Nagrial AM, Humphris J, Chantrill LA, Chin V, Steinmann AM, Mawson A, Humphrey ES, Colvin EK, Chou A, Scarlett CJ, Pinho AV, Giry-Laterriere M, Rooman I, Samra JS, Kench JG, Pettitt JA, Merrett ND, Toon C, Epari K, Nguyen NQ, Barbour A, Zeps N, Jamieson NB, Graham JS, Niclou SP, Bjerkvig R, Grützmann R, Aust D, Hruban RH, Maitra A, Iacobuzio-Donahue CA, Wolfgang CL, Morgan RA, Lawlor RT, Corbo V, Bassi C, Falconi M, Zamboni G, Tortora G, Tempero MA, Gill AJ, Eshleman JR, Pilarsky C, Scarpa A, Musgrove EA, Pearson JV, Biankin AV, Grimmond SM and Grimmond SM: Whole genomes redefine the mutational landscape of pancreatic cancer. Nature 518: 495-501, 2015.

6 Cowan RW and Maitra A: Genetic progression of pancreatic cancer. Cancer J 20: 80-84, 2014.

7 Chan A, Diamandis EP and Blasutig IM: Strategies for discovering novel pancreatic cancer biomarkers. J Proteomics 81: 126-134, 2013.

8 Ducreux M, Cuhna AS, Caramella C, Hollebecque A, Burtin P, Goéré D, Seufferlein T, Haustermans K, Van Laethem JL, Conroy T, Arnold D and ESMO Guidelines Committee: Cancer of the pancreas: ESMO Clinical Practice Guidelines for diagnosis, treatment and follow-up. Ann Oncol 26: v56-v68, 2015.

9 Tumas J, Kvederaviciute K, Petrulionis M, Kurlinkus B, Rimkus A, Sakalauskaite G, Cicenas J and Sileikis A: Metabolomics in pancreatic cancer biomarkers research. Med Oncol 33: 133, 2016.

10 Sileikis A, Petrulionis M, Kurlinkus B, Ger M, Kaupinis A, Cicenas J, Valius M and Strupas K: Current role of proteomics in pancreatic cancer biomarkers research. Curr Proteomics 13: 68-75, 2016.

11 Pihlak R, Weaver J, Valle $\mathrm{J}$ and McNamara M: Advances in molecular profiling and categorisation of pancreatic adenocarcinoma and the implications for therapy. Cancers (Basel) 10: 17, 2018.

12 Börner A, Warnken U, Schnölzer M, Hagen J von, Giese N, Bauer A and Hoheisel JD: Subcellular protein extraction from human pancreatic cancer tissues. Biotechniques 46: 297-304, 2009.

13 Ger M, Kaupinis A, Nemeikaite-Ceniene A, Sarlauskas J, Cicenas $\mathrm{J}$, Cenas $\mathrm{N}$ and Valius M: Quantitative proteomic analysis of anticancer drug RH1 resistance in liver carcinoma. Biochim Biophys Acta - Proteins Proteomics 1864: 219-232, 2016.

14 Zhou H, Telonis AG, Jing Y, Xia NL, Biederman L, Jimbo M, Blanco F, Londin E, Brody JR and Rigoutsos I: GPRC5A is a potential oncogene in pancreatic ductal adenocarcinoma cells that is upregulated by gemcitabine with help from HuR. Cell Death Dis 7: e2294-e2294, 2016.

15 McCarthy DM, Maitra A, Argani P, Rader AE, Faigel DO, Van Heek NT, Hruban RH and Wilentz RE: Novel markers of pancreatic adenocarcinoma in fine-needle aspiration: mesothelin and prostate stem cell antigen labeling increases accuracy in cytologically borderline cases. Appl Immunohistochem Mol Morphol AIMM 11: 238-243, 2003.

16 Spratlin JL and Mulder KE: Looking to the future: biomarkers in the management of pancreatic adenocarcinoma. Int J Mol Sci 12: 5895-5907, 2011.

17 Kirkegård J, Mortensen FV and Cronin-Fenton D: Chronic pancreatitis and pancreatic cancer risk: A systematic review and meta-analysis. Am J Gastroenterol 112: 1366-1372, 2017.

18 Guerra C, Schuhmacher AJ, Cañamero M, Grippo PJ, Verdaguer L, Pérez-Gallego L, Dubus P, Sandgren EP and Barbacid M:
Chronic pancreatitis is essential for induction of pancreatic ductal adenocarcinoma by K-Ras oncogenes in adult mice. Cancer Cell 11: 291-302, 2007.

19 Choi HS, Hwang CK, Song KY, Law P-Y, Wei L-N and Loh $\mathrm{HH}$ : Poly $(\mathrm{C})$-binding proteins as transcriptional regulators of gene expression. Biochem Biophys Res Commun 380: 431-436, 2009.

20 Choi HS, Kim CS, Hwang CK, Song KY, Law P-Y, Wei L-N and Loh HH: Novel function of the poly(C)-binding protein $\alpha \mathrm{CP} 3$ as a transcriptional repressor of the mu opioid receptor gene. FASEB J 21: 3963-3973, 2007.

21 Choi HS, Song KY, Hwang CK, Kim CS, Law P-Y, Wei L-N and Loh HH: A proteomics approach for identification of single strand DNA-binding proteins involved in transcriptional regulation of mouse $\mu$ opioid receptor gene. Mol Cell Proteomics 7: 1517-1529, 2008.

22 Ito Y, Narita N, Nomi N, Sugimoto C, Takabayashi T, Yamada T, Karaya K, Matsumoto $\mathrm{H}$ and Fujieda S: Suppression of poly(rC)-binding protein 4 (PCBP4) reduced cisplatin resistance in human maxillary cancer cells. Sci Rep 5: 12360, 2015.

23 El Fitori J, Su Y, Büchler P, Ludwig R, Giese NA, Büchler MW, Quentmeier H, Hines OJ, Herr I and Friess H: PKC 412 smallmolecule tyrosine kinase inhibitor. Cancer 110: 1457-1468, 2007.

24 Dong J, McPherson CM and Stambrook PJ: Flt-3 ligand: a potent dendritic cell stimulator and novel antitumor agent. Cancer Biol Ther 1: 486-489, 2002.

25 Tjomsland V, Spångeus A, Sandström P, Borch K, Messmer D and Larsson M: Semi mature blood dendritic cells exist in patients with ductal pancreatic adenocarcinoma owing to inflammatory factors released from the tumor. PLoS One 5: e13441, 2010.

26 Fukunaga A, Miyamoto M, Cho Y, Murakami S, Kawarada Y, Oshikiri T, Kato K, Kurokawa T, Suzuoki M, Nakakubo Y, Hiraoka K, Itoh T, Morikawa T, Okushiba S, Kondo S and Katoh $\mathrm{H}$ : CD8+ tumor-infiltrating lymphocytes together with CD4+ tumor-infiltrating lymphocytes and dendritic cells improve the prognosis of patients with pancreatic adenocarcinoma. Pancreas 28: e26-31, 2004.

27 Wartenberg M, Cibin S, Zlobec I, Vassella E, EppenbergerCastori S, Terracciano L, Eichmann MD, Worni M, Gloor B, Perren A and Karamitopoulou E: Integrated genomic and immunophenotypic classification of pancreatic cancer reveals three distinct subtypes with prognostic/predictive significance. Clin Cancer Res, 2018. doi: 10.1158/1078-0432.CCR-17-3401. [Epub ahead of print]

28 Bailey P, Chang DK, Nones K, Johns AL, Patch A-M, Gingras M-C, Miller DK, Christ AN, Bruxner TJC, Quinn MC, Nourse C, Murtaugh LC, Harliwong I, Idrisoglu S, Manning S, Nourbakhsh E, Wani S, Fink L, Holmes O, Chin V, Anderson MJ, Kazakoff S, Leonard C, Newell F, Waddell N, Wood S, Xu Q, Wilson PJ, Cloonan N, Kassahn KS, Taylor D, Quek K, Robertson A, Pantano L, Mincarelli L, Sanchez LN, Evers L, Wu J, Pinese M, Cowley MJ, Jones MD, Colvin EK, Nagrial AM, Humphrey ES, Chantrill LA, Mawson A, Humphris J, Chou A, Pajic M, Scarlett CJ, Pinho A V., Giry-Laterriere M, Rooman I, Samra JS, Kench JG, Lovell JA, Merrett ND, Toon CW, Epari K, Nguyen NQ, Barbour A, Zeps N, Moran-Jones K, Jamieson NB, Graham JS, Duthie F, Oien K, Hair J, Grützmann R, Maitra A, Iacobuzio-Donahue CA, Wolfgang CL, Morgan RA, Lawlor RT, Corbo V, Bassi C, Rusev B, Capelli P, Salvia R, Tortora G, 
Mukhopadhyay D, Petersen GM, Munzy DM, Fisher WE, Karim SA, Eshleman JR, Hruban RH, Pilarsky C, Morton JP, Sansom OJ, Scarpa A, Musgrove EA, Bailey U-MH, Hofmann O, Sutherland RL, Wheeler DA, Gill AJ, Gibbs RA, Pearson JV, Waddell N, Biankin AV, Grimmond SM and Grimmond SM: Genomic analyses identify molecular subtypes of pancreatic cancer. Nature 531: 47-52, 2016.

29 Okamoto M, Kobayashi M, Yonemitsu Y, Koido S and Homma S: Dendritic cell-based vaccine for pancreatic cancer in Japan. World J Gastrointest Pharmacol Ther 7: 133-138, 2016.

30 Braun SE, Chen K, Blazar BR, Orchard PJ, Sledge G, Robertson MJ, Broxmeyer HE and Cornetta K: Flt3 ligand antitumor activity in a murine breast cancer model: A comparison with granulocytemacrophage colony-stimulating factor and a potential mechanism of action. Hum Gene Ther 10: 2141-2151, 1999.
31 Disis ML, Rinn K, Knutson KL, Davis D, Caron D, dela Rosa $\mathrm{C}$ and Schiffman K: Flt3 ligand as a vaccine adjuvant in association with HER-2/neu peptide-based vaccines in patients with HER-2/neu-overexpressing cancers. Blood 99: 2845-2850, 2002.
Received August 6, 2018

Revised August 22, 2018

Accepted August 28, 2018 